[miejsce życia]

\title{
Panorama Drohobycza z 1907 roku i inne ujęcia miasta. Ze zbio- rów Zbigniewa Milczarka
}

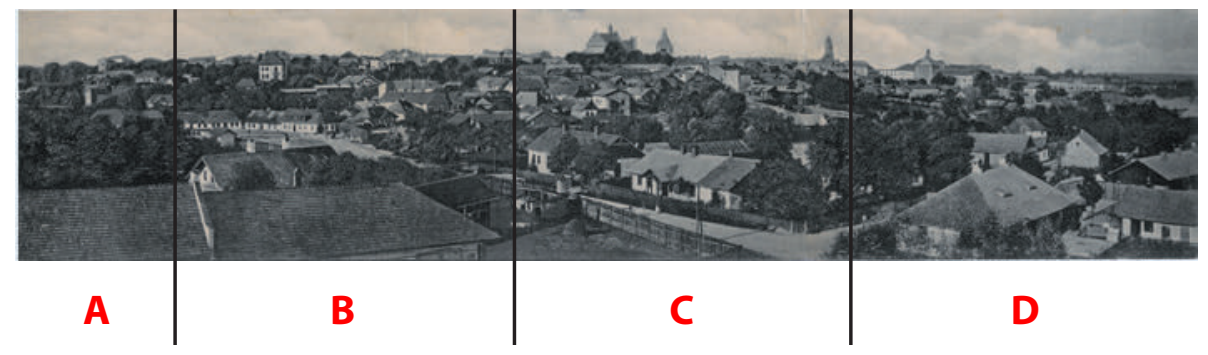




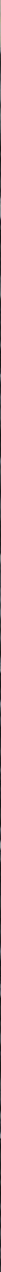

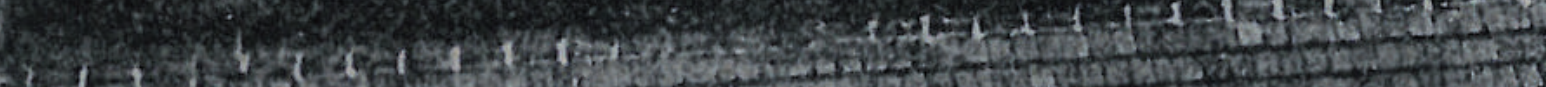

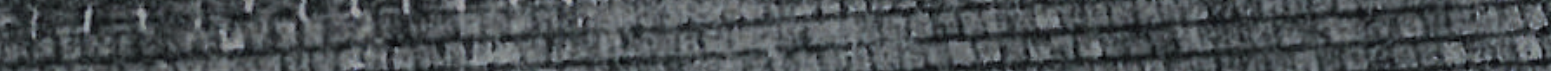

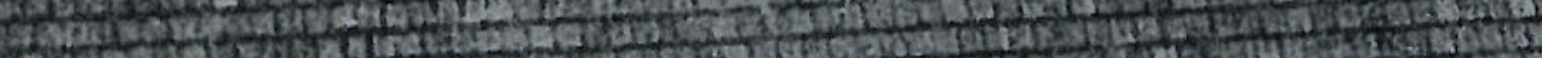

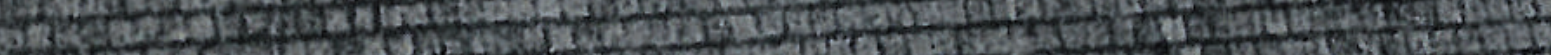
to

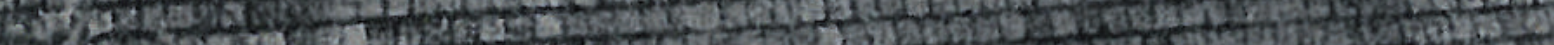

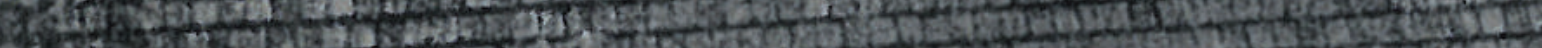

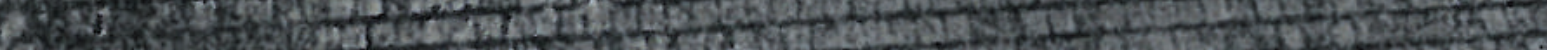

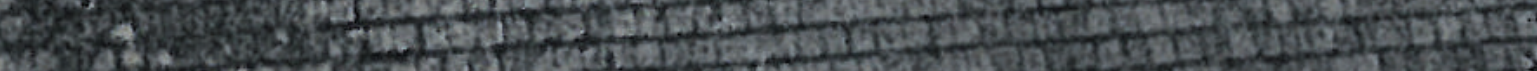

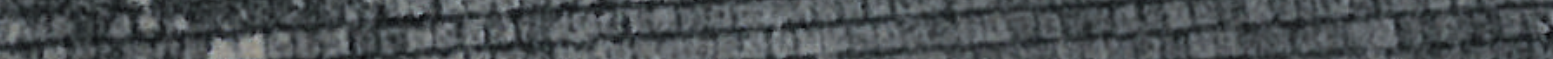

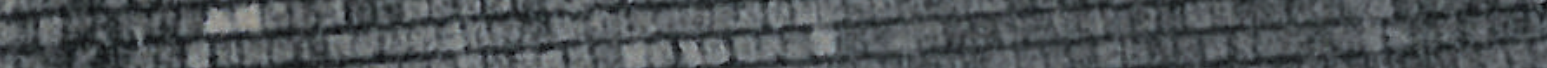

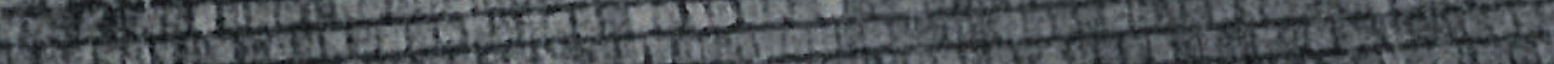

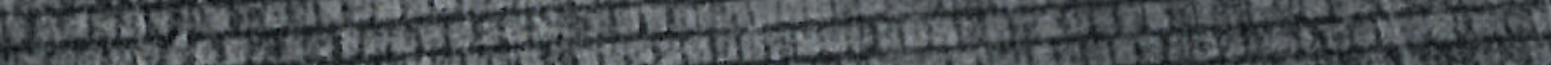
s.m.

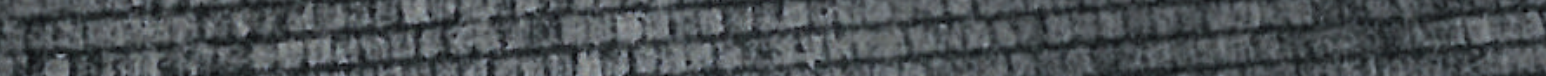

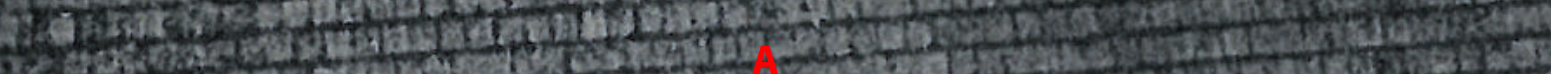

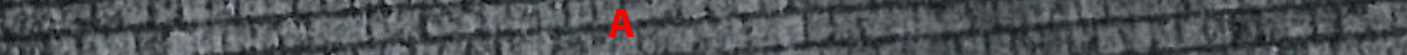

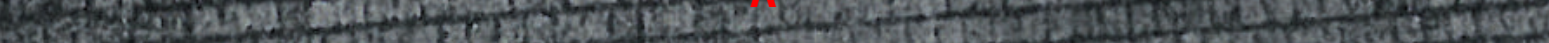

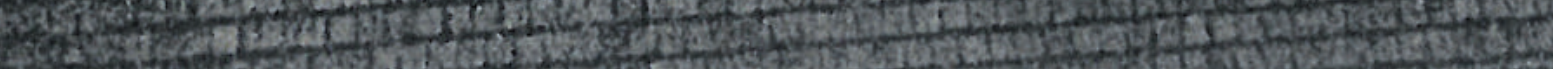




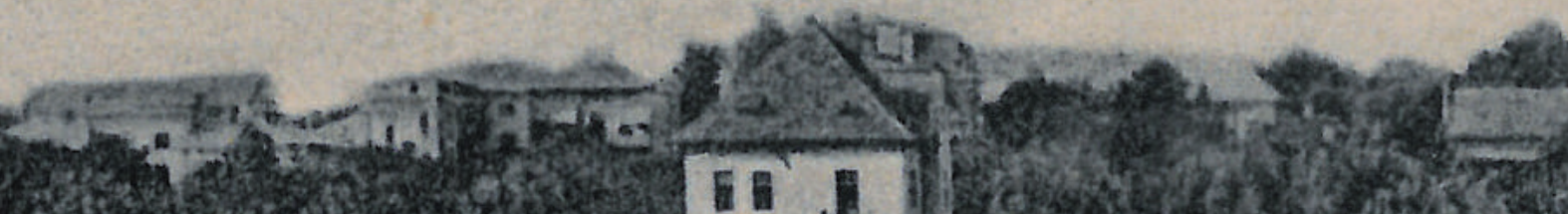
int in in

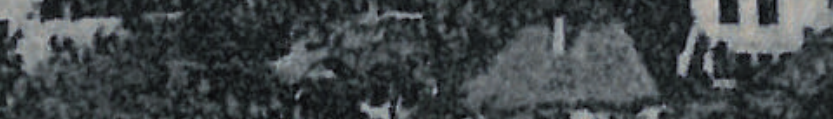
4t. - resoner (4)

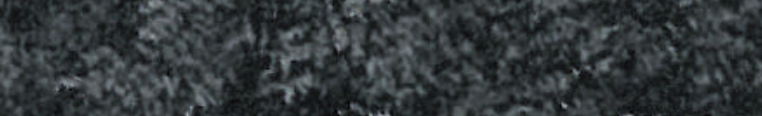

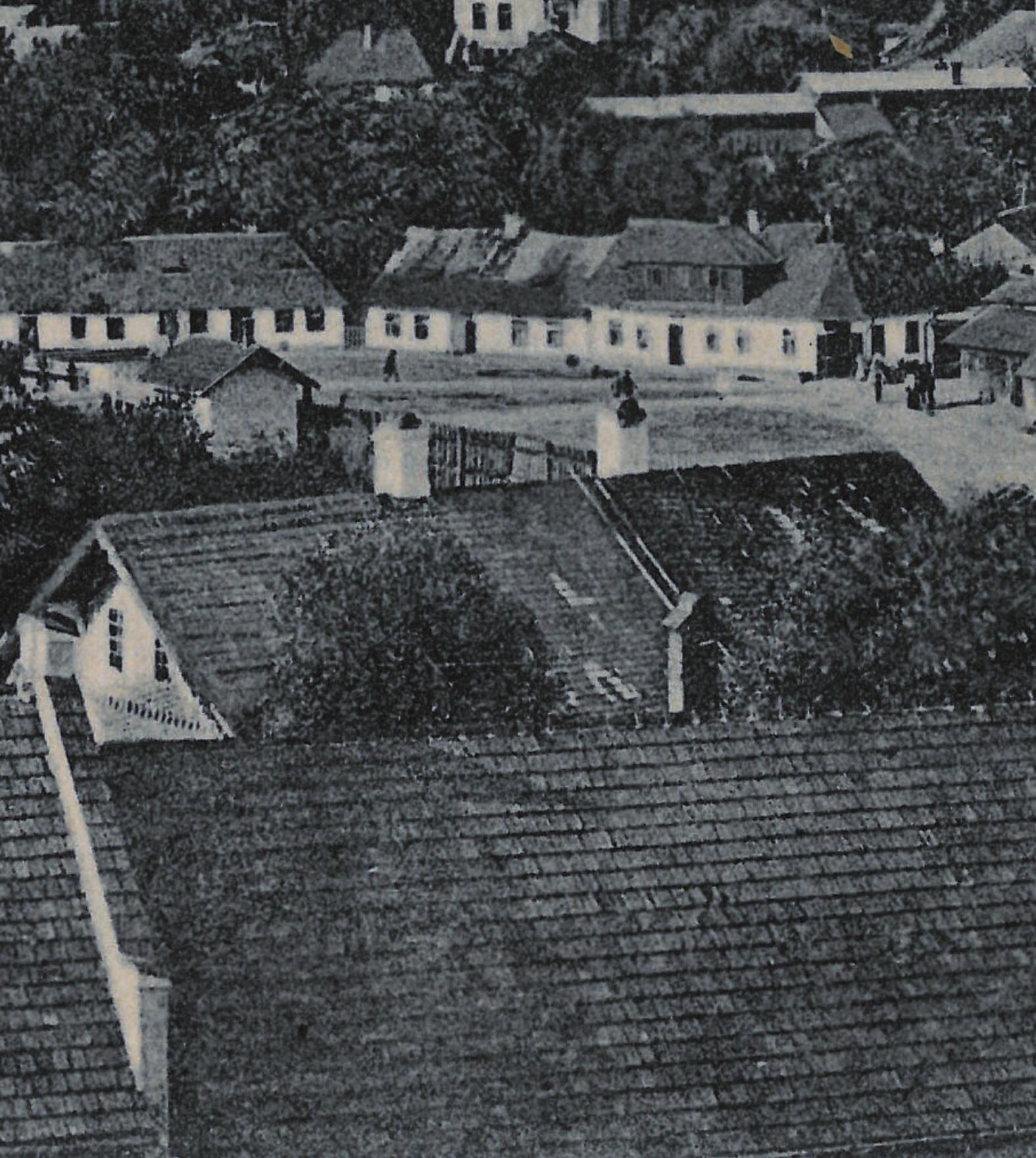




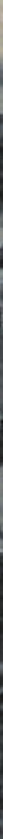
and -.

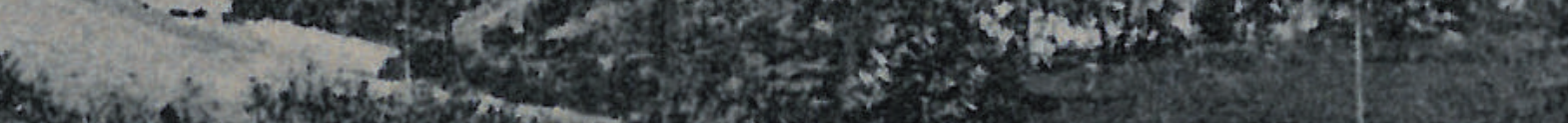

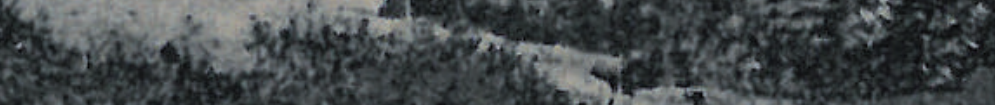
1.7. (2) Ant

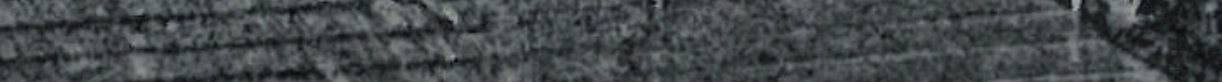

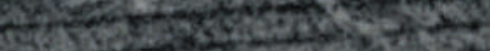
2010 L

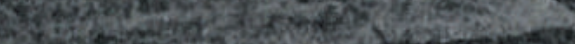
P.

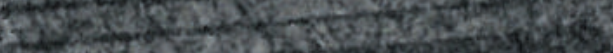




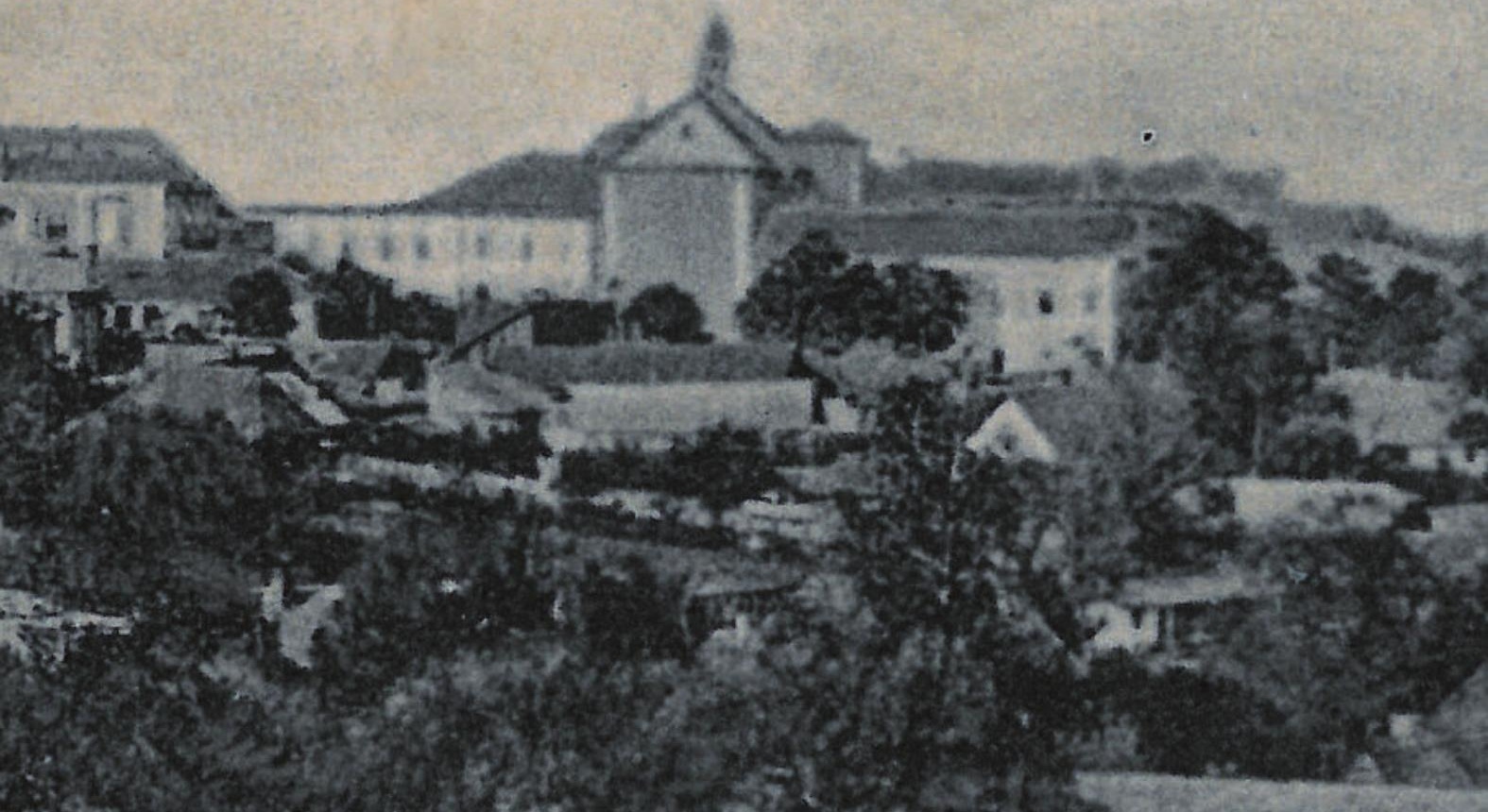

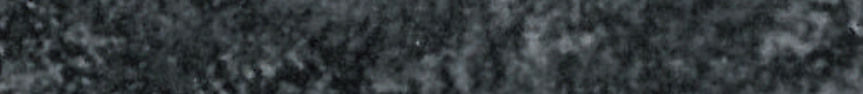

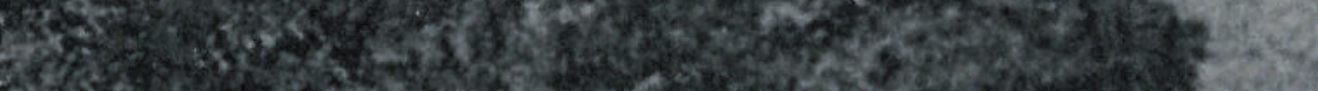

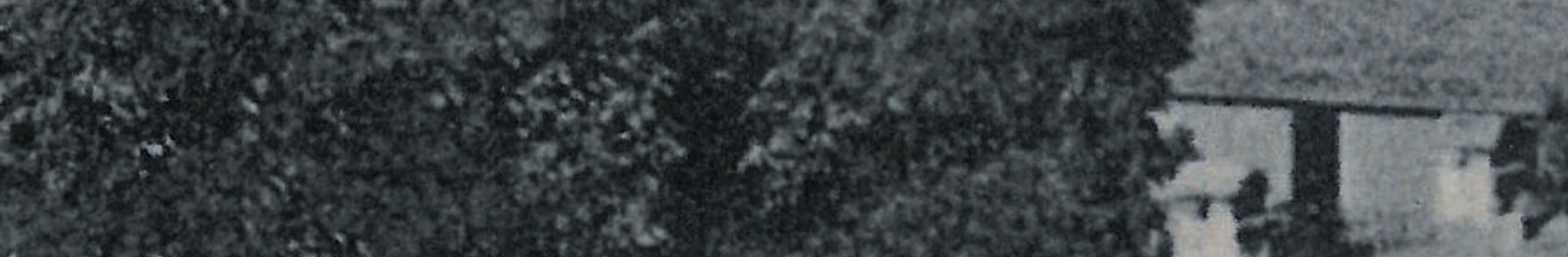

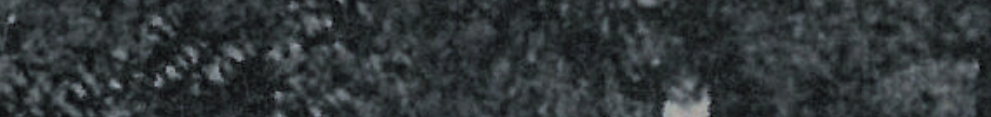
(9) 4 - 1

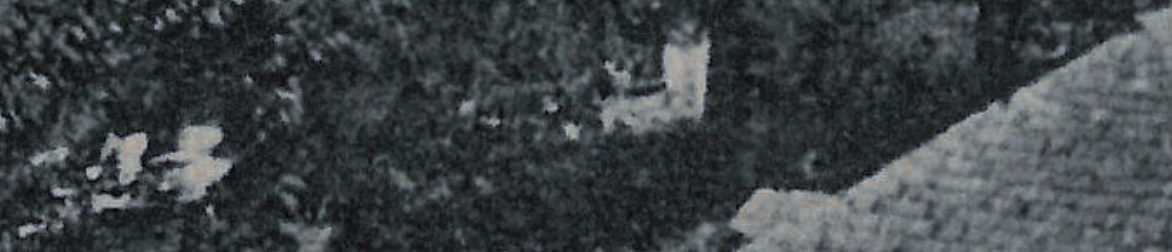

wish 8 (1) Mor.

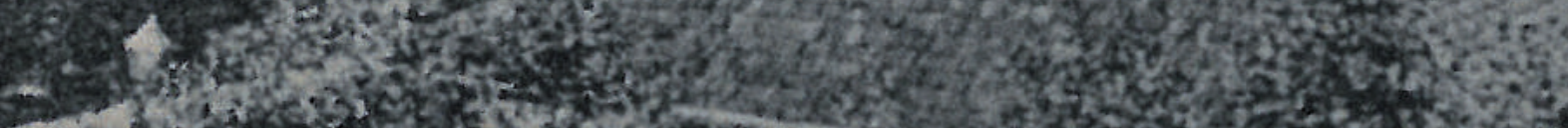

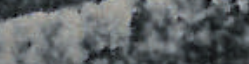

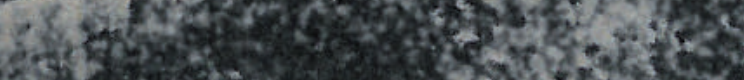
2.3.5.

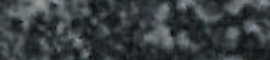

S.

$5^{2}$

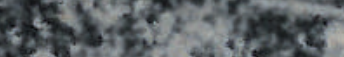

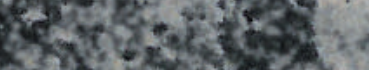

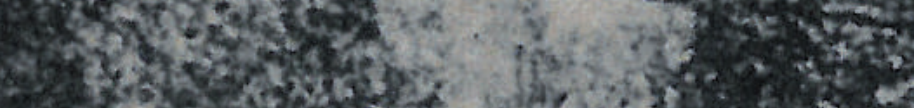
स.

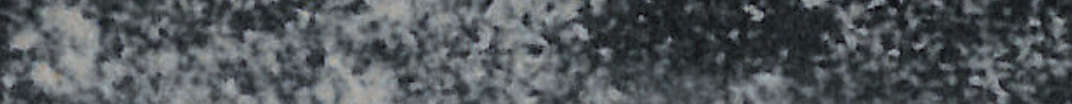

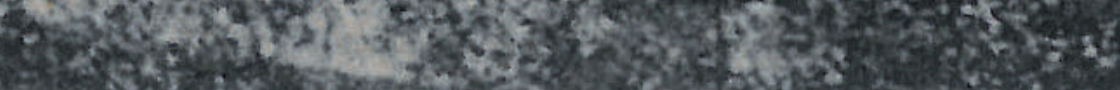




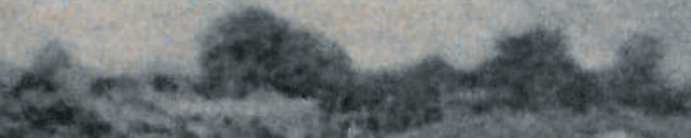

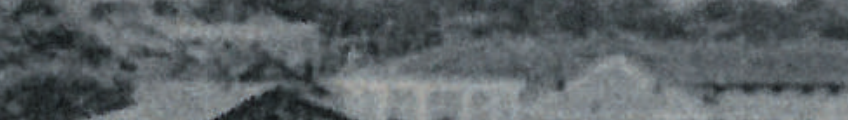

5.

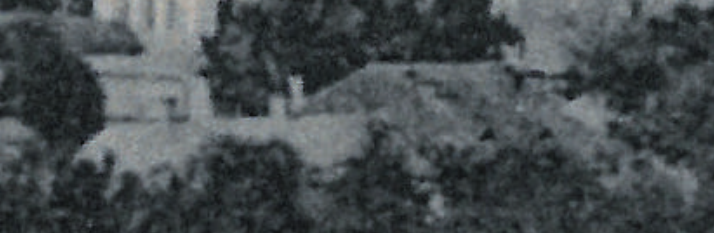

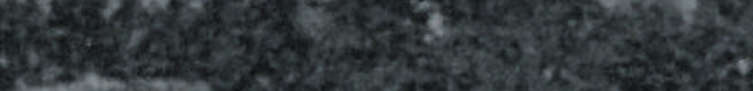

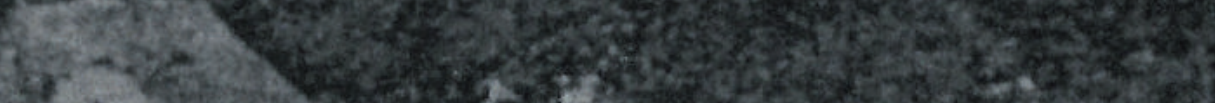

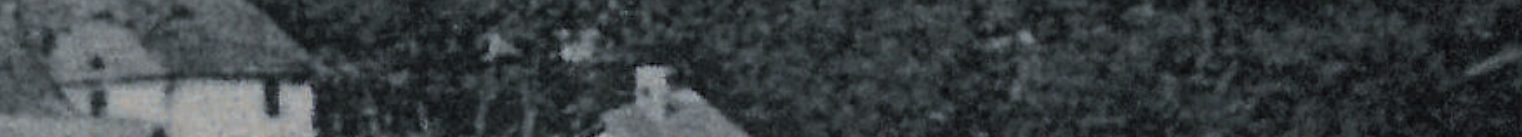

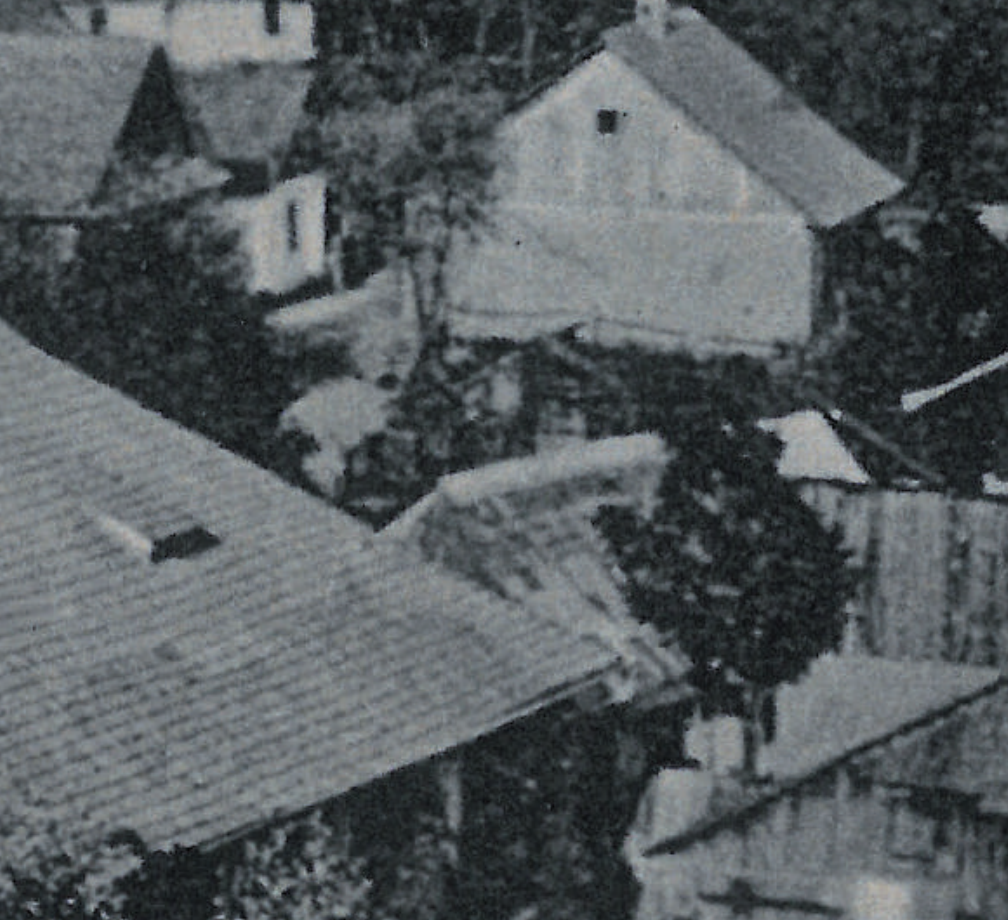

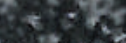

H sing 20 N. C.t.

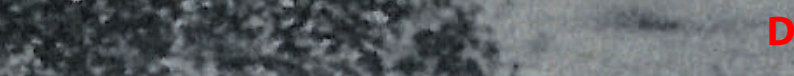

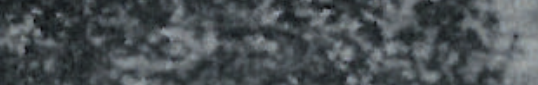
Hertas,

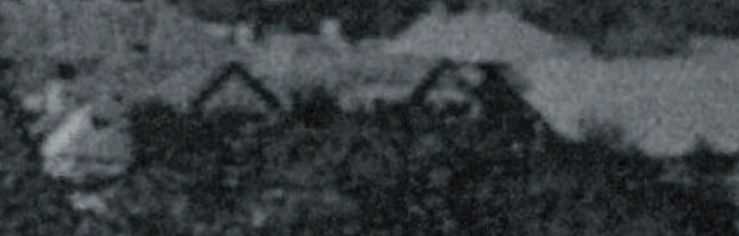


Lisznia 

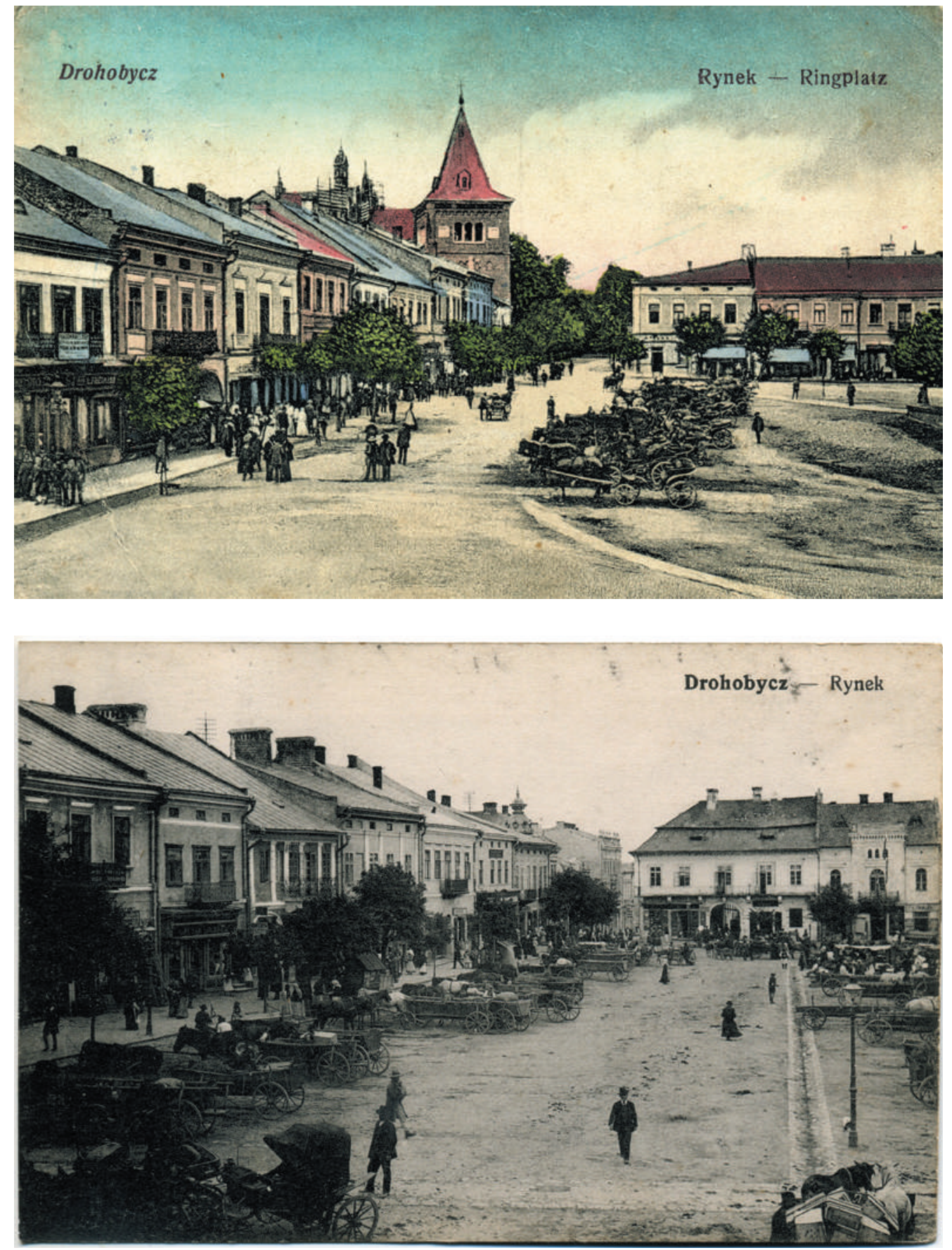

Rynek - Ringplatz, L. Rosenschein, przed 1920 Drohobycz - Rynek, L. Rosenschein, 1915

Plan miasta Drohobycza (fragment), Polski informator gospodarczy miasta Drohobycza. Nakładem Stowarzyszenia Kupców i Przemysłowców Polskich Ziem PołudniowoWschodnich - Oddział w Drohobyczu, 1925-1929 


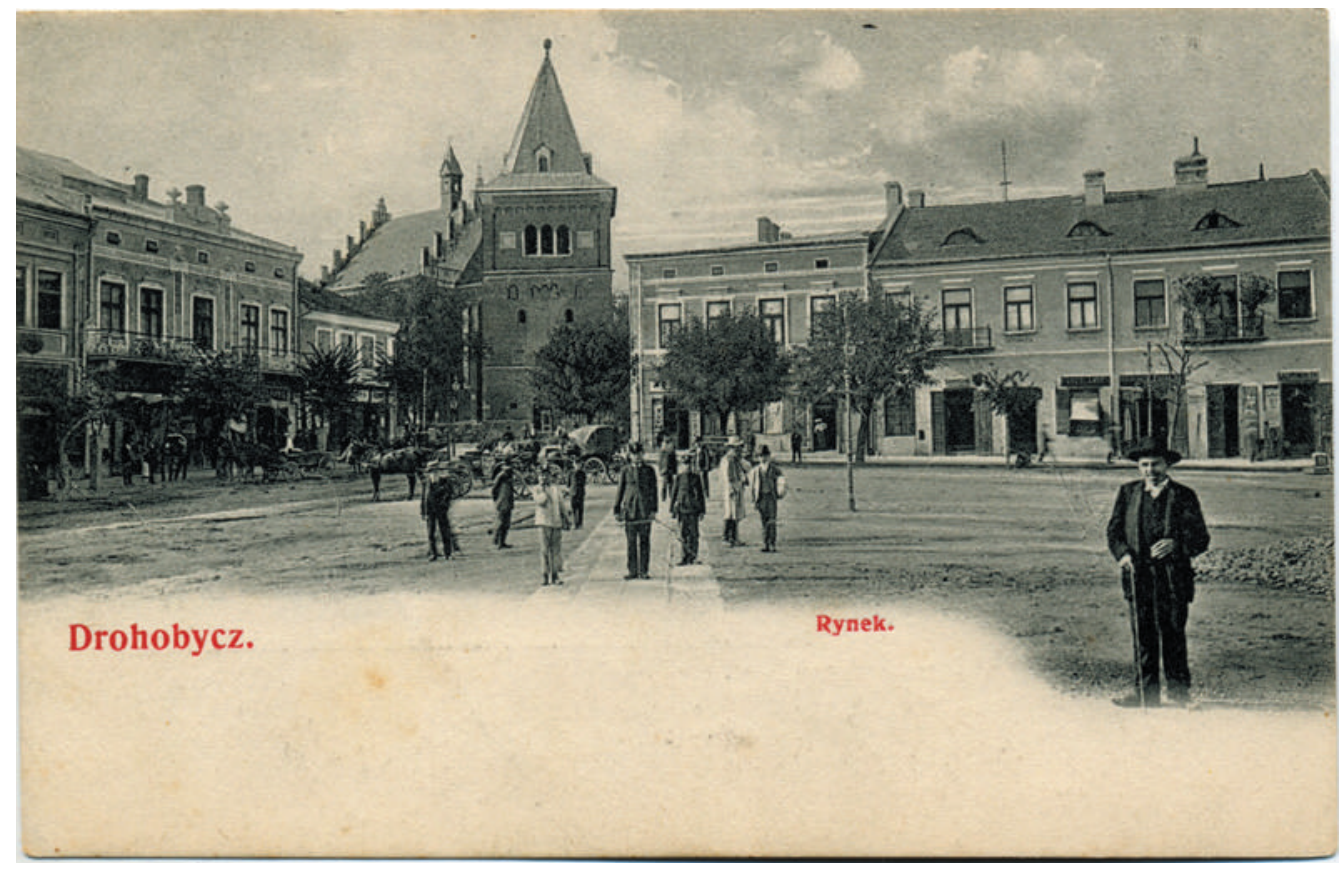

Rynek, początek XX wieku

Drohobycz - Kościół, Wydawnictwo Kart Widokowych Księgarni J. Pilpla w Drohobyczu, początek XX wieku 


\section{Drohobycz.}

Kossciól.

\section{ㄷ}
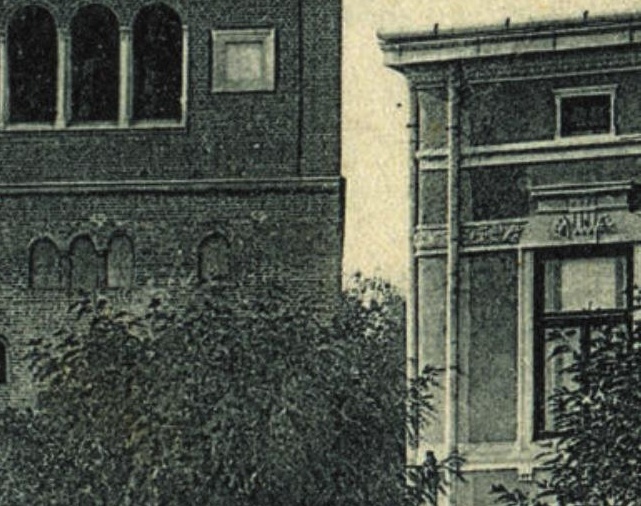
$x+21 \rightarrow 5$ $x^{2} \rightarrow \frac{1}{2}$

\section{2}

)

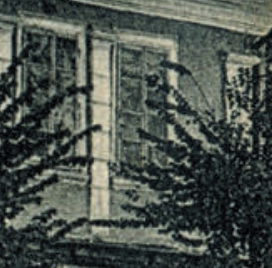

HMI! $1=2$

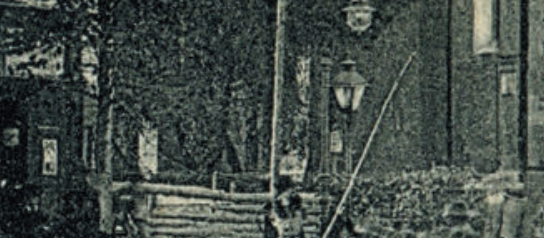

(5)

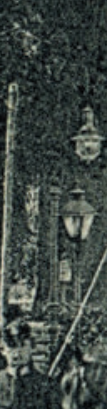

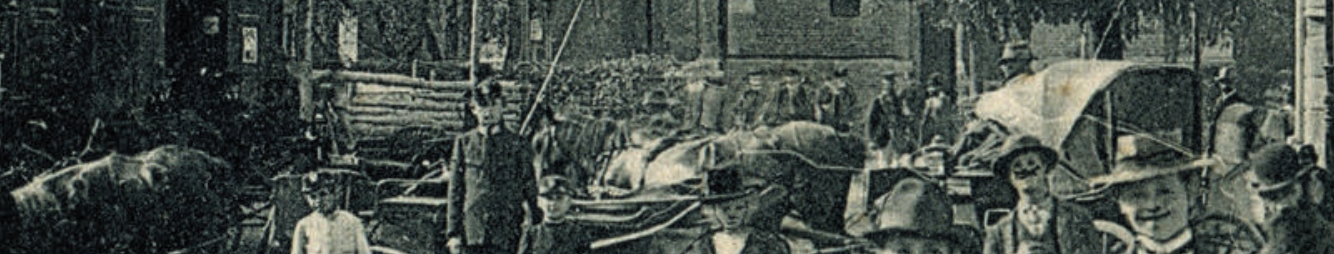
n. 1) 2 (t)

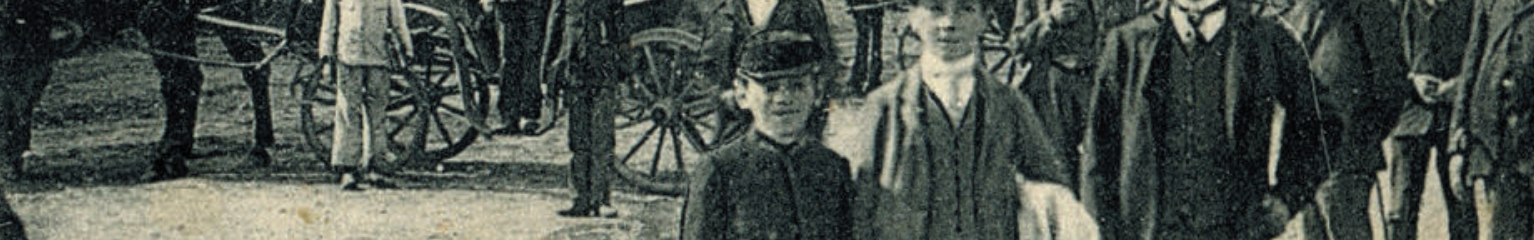

\section{t.}

-ant 


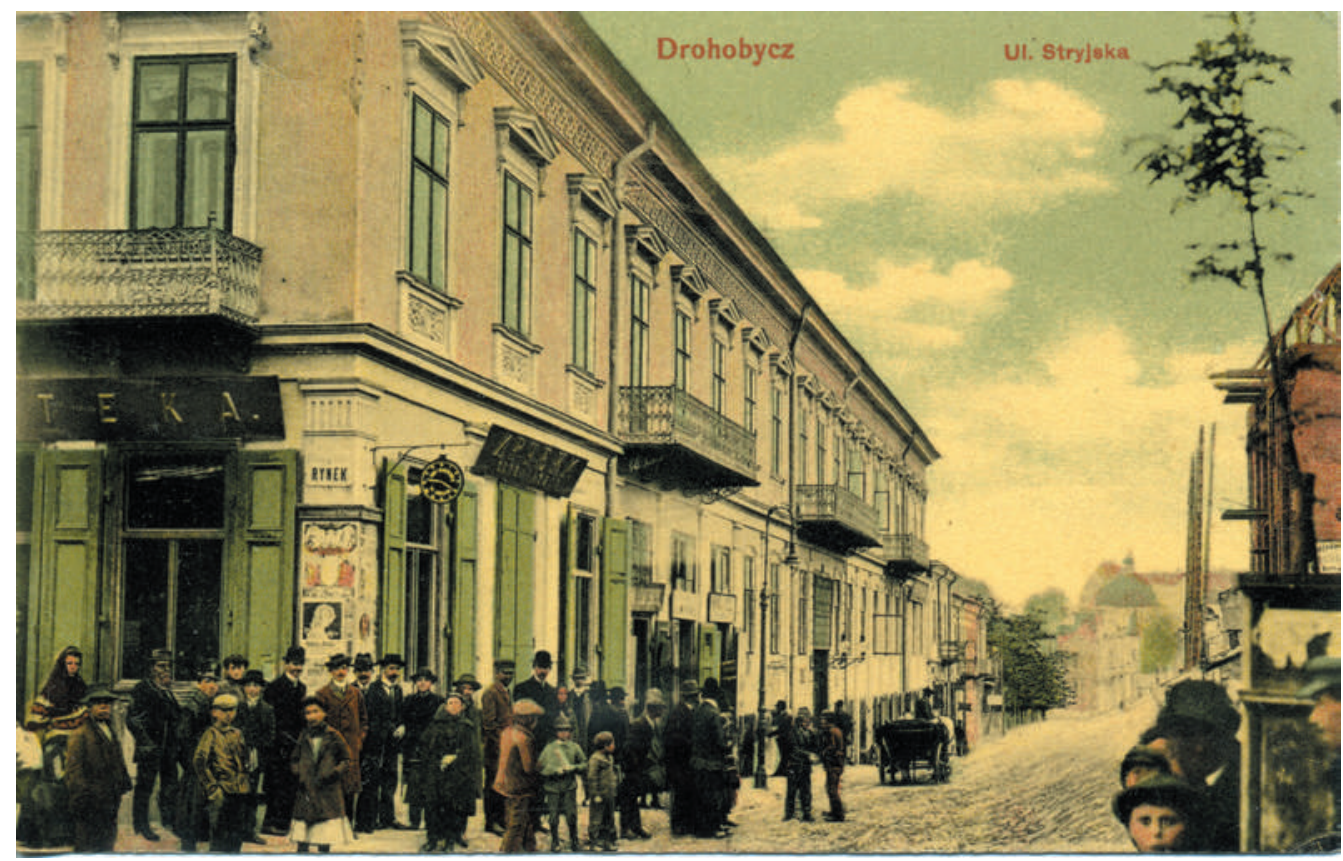

Ulica Stryjska, Wydawnictwo Kart Widokowych

Księgarni J. Pilpla w Drohobyczu, 1909 


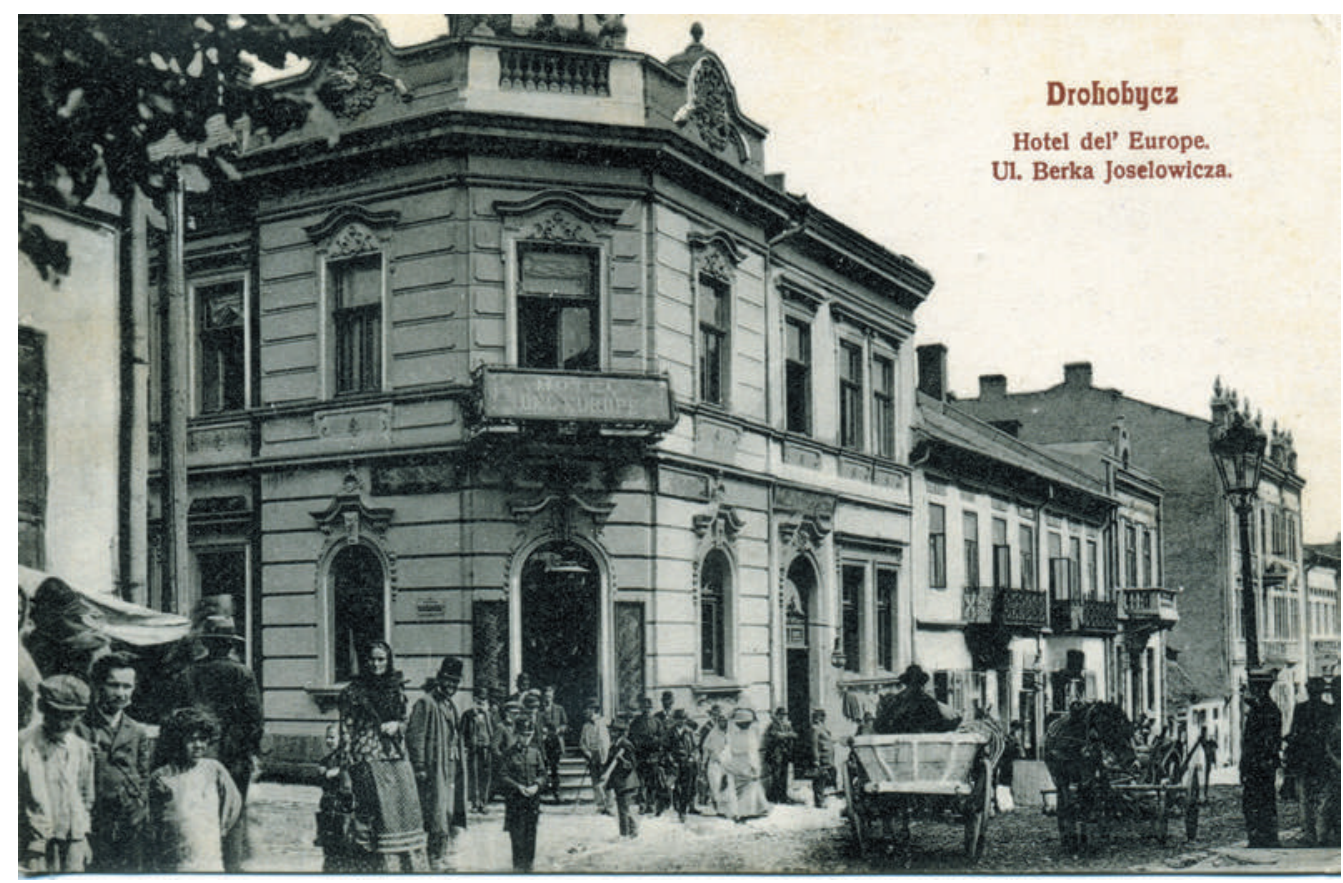

Hotel del' Europe, L. Rosenschein, 1911 


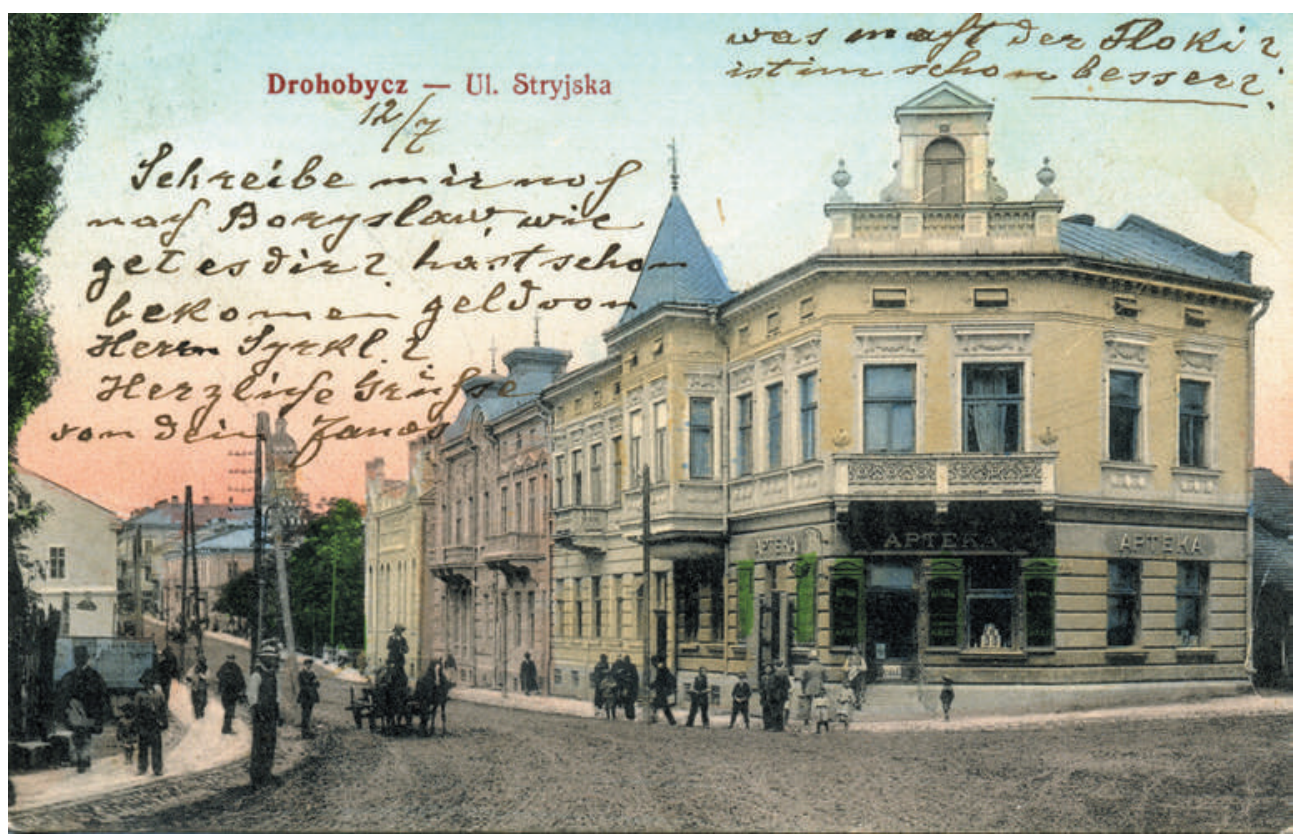

Ulica Stryjska, L. Rosenschein, 1912

Ulica Stryjska, początek XX wieku 


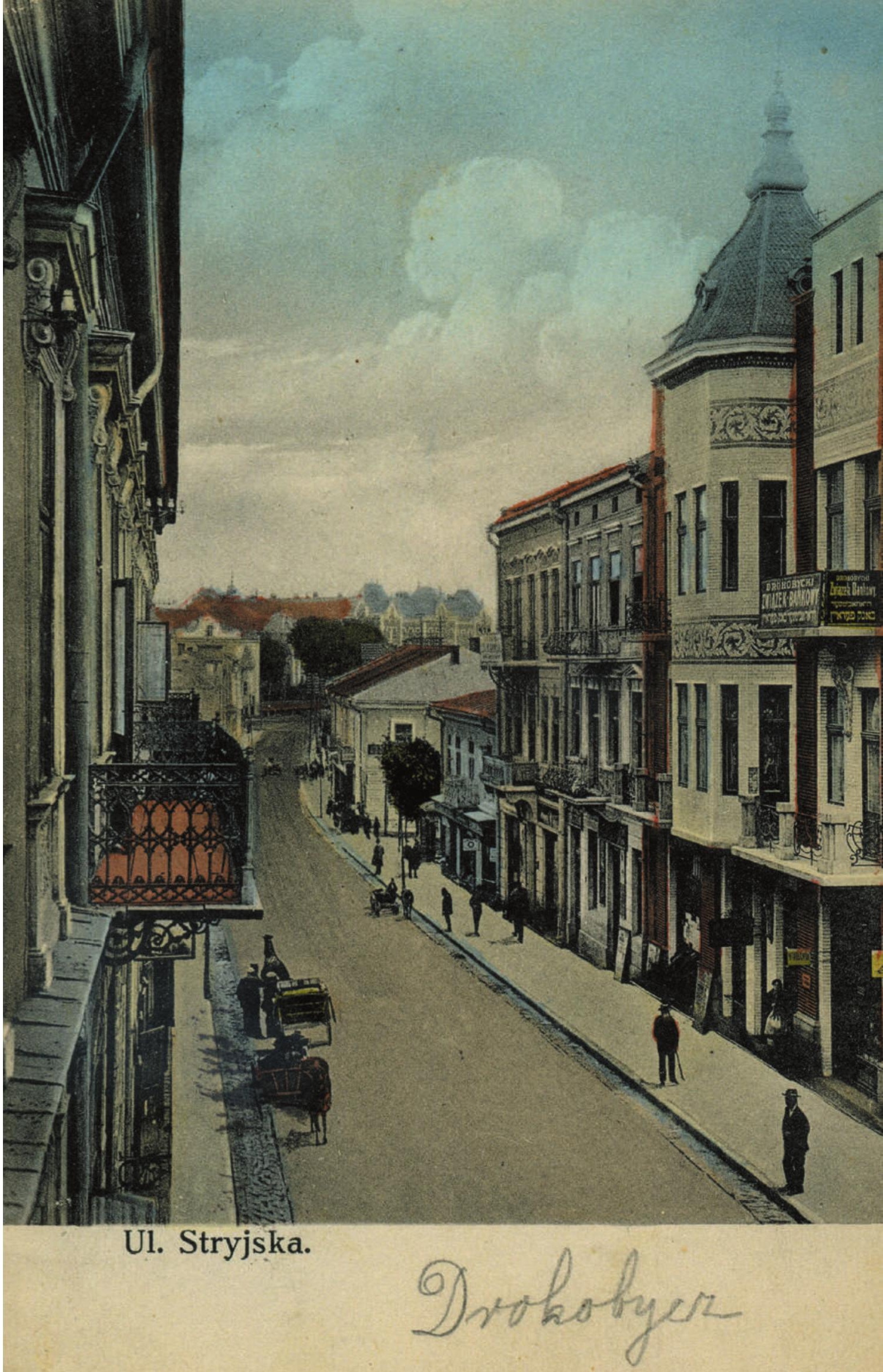





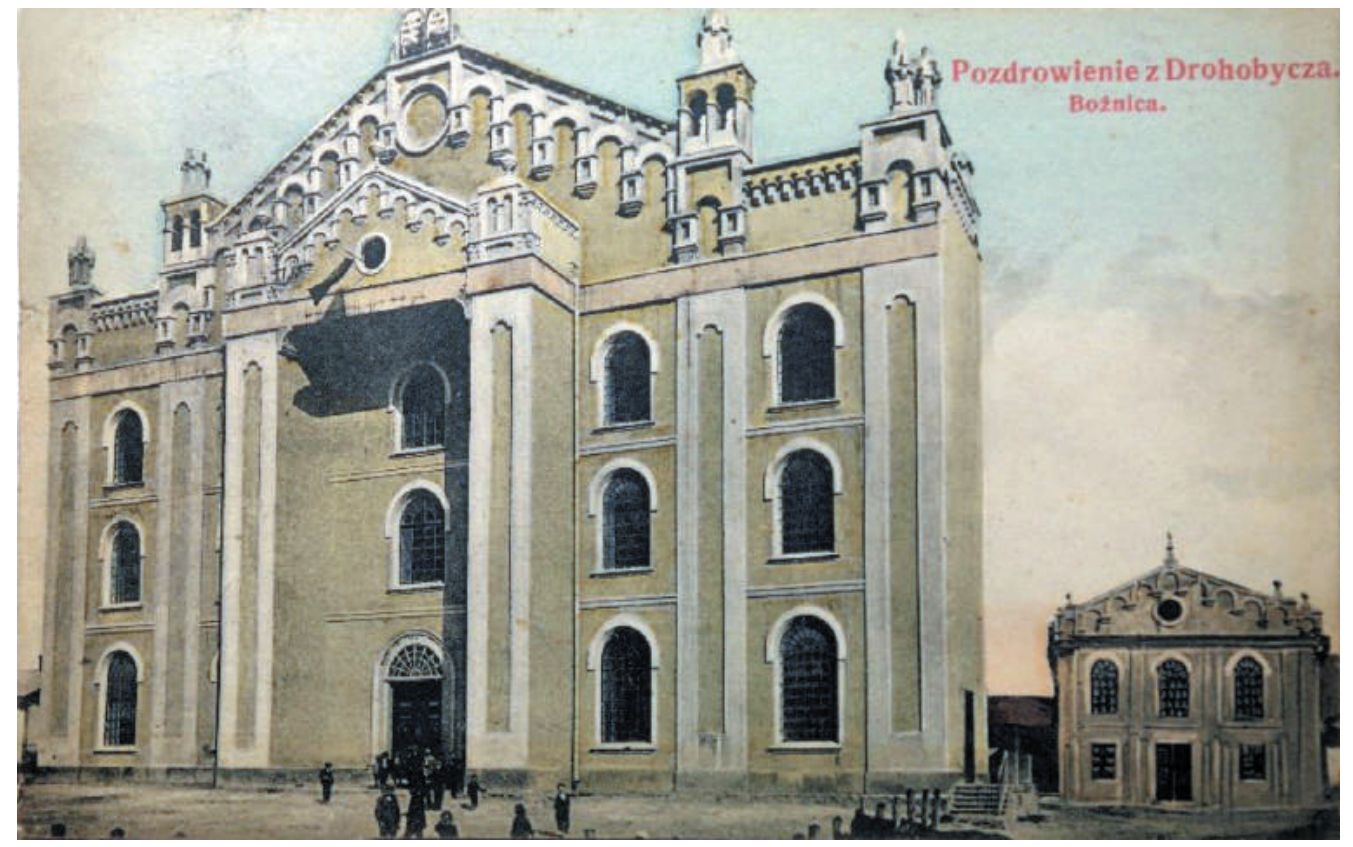

Bożnica, Wydawnictwo Kart Widokowych Księgarni J. Pilpla w Drohobyczu, początek XX wieku

Cerkiew św. Trójcy, Wydawnictwo Kart Widokowych Księgarni J. Pilpla w Drohobyczu, ok. 1909 (fragment) 

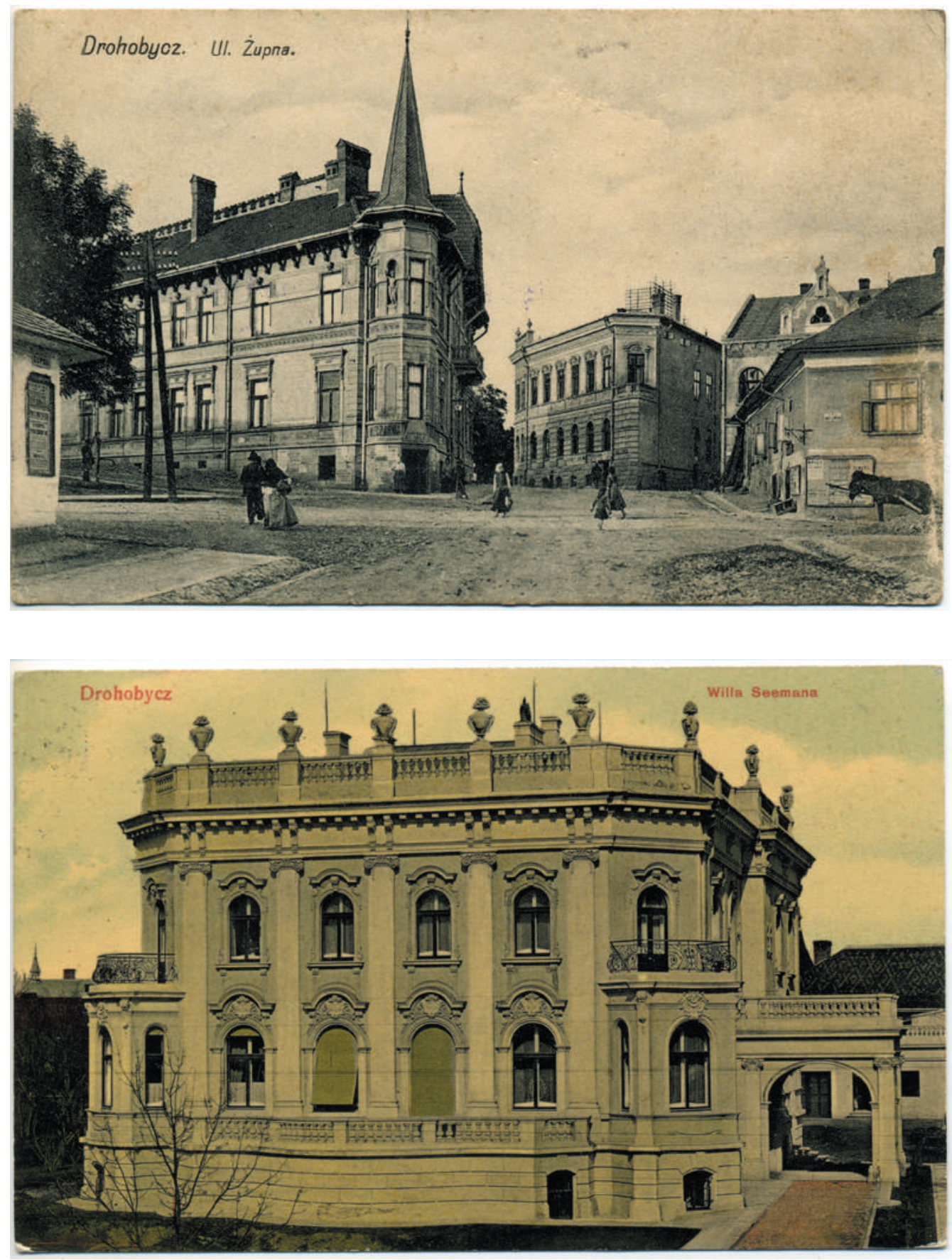

Ulica Żupna, L. Rosenschein, 1913

Willa Seemana, Wydawnictwo Kart Widokowych

Księgarni J. Pilpla w Drohobyczu, 1909 